\title{
A Fuzzy Sets Model for Companies Behaviour of Absorption Minimum Wage Shocks: An Analysis of Inflationary Risks
}

\author{
Dorel Ailenei, Coralia Angelescu, Amalia Cristescu and Mihaela Hrisanta \\ Economics and Economic Policies Department, Faculty of Economics, \\ Academy of Economic Studies Bucharest, Romania
}

\begin{abstract}
The minimum wage appears to be a new challenge for emerging labor market from Romania. Is this a real problem or only a theoretical shadow of some unclear model of market economy? The authors tried to bring to light the real effects of minimum wage increases during the last decade in Romania and to identify some potential inflationary risks of this phenomenon. For that, they used some econometric test of relationships between minimum wage and average gross nominal wage, rate of employment and consumer prices index dynamics, a national survey of Romanian companies and elaborated a fuzzy sets model for companies' behaviors for absorbing minimum wage shocks.
\end{abstract}

Keywords: fuzzy set model, minimum wage shocks, inflationary risks, company behavior

\section{Introduction}

The problem of minimum wage is one of most controversial topic of labor market economics. A minimum wage was first implemented in the United States with Fair Labor Standards Act of 1938, which now covers more than $90 \%$ of all workers. Since its enactment, there has been widespread debate about the merits of minimum wage laws, along with numerous efforts to evaluate their economic effects. By the early 1980s, the amassed body of theoretical and empirical research by economists, including that of the Minimum Wage Study Commission (1981), suggested that the imposition of minimum wages decreases employment opportunities for workers with wages at or near the minimum wage (Brown et al. 1982; Brown 1988).
The great majority of EU Member States have some form of statutory national minimum wage, but there are also many collective agreements playing the main role in setting minimum pay rates for the rest of countries. The near universal application of wage floors in developed economies is evidence that the minimum wage as a policy tool has been less controversial amongst policymakers than it has among economists and academics. In principle, minimum wages are a subject of contention between the social partners and government. However, in two countries that were late to adopt minimum wages, the UK (1997) and Ireland (1999), initial opposition from employer organizations has mellowed, with reservations being expressed only about the level at which the minimum wage is set. Impact assessments tend to confirm that productivity increases have been such that

Copyright (C2011 Dorel AILENEI, Coralia Angelescu, Amalia Cristescu and Mihaela Hrisanta. This is an open access article distributed under the Creative Commons Attribution License unported 3.0, which permits unrestricted use, distribution, and reproduction in any medium, provided that original work is properly cited. Contact author: Dorel AILENEI e-maill: dailenei@economie.ase.ro 
the introduction of the minimum wage has not brought about 'any general increase in aggregate unit labor costs' in typically lowpaying sectors (textiles, retail etc.) (Arrowsmith, 2005).

The minimum wage directly affects a small minority of wage-earners less than $16 \%$ in the EU overall and less than $5 \%$ in the majority of countries with a statutory minimum wage. It is, however, of particular importance in supporting the pay of women, younger workers (despite widespread subminima) and those in low-paying sectors such as textiles, retail, hotels and restaurants, etc.

\section{Theoretical Effect of Minimum Wage Increases}

In a context of growing wage inequality, often assumed to be a structural one, the differential between low earners and medium earners has not widened as much as that between medium and high earners in recent years. In this respect, minimum wages along with other complementary measures (reduced tax on low wages, in-work benefits and maintenance or extension of social benefits for the low paid) may have had some role in cushioning the impact of forces - such as technological diffusion, off shoring, and low-wage competition from Third World countries - that would otherwise have further depressed low wages in Europe (Adam, 2007).

The minimum wage alone may have limited direct impact in terms of inequality or poverty reducing. It is, however, increasingly seen as an important means of contributing to such policy objectives when taken in conjunction with supporting fiscal, social security and training and activation measures.

Neumark and Wascher (2008) published an analysis of over 300 studies on the minimum wage. The studies were from several countries covering a period of over 50 years, primarily from the 1990s onward. According to the Neumark and Wascher, a large majority of the studies show negative effects for the minimum wage; those showing positive effects are few, questionable, and disproportionately discussed. Neumark and Wascher conclude that the minimum wage is not a good social policy. They emphasize three especially salient conclusions: First, they found that studies since the early 1990s have strongly pointed to a "reduction in employment opportunities for low-skilled and directly affected workers." Second, they found some evidence that the minimum wage is harmful to poverty-stricken families and "virtually no evidence" that it helps them. Third, they found that the minimum wage lowers adult wages of young workers who encounter it, by reducing their ultimate level of education.

There is an extensive literature about the effect of an effective minimum wage on employment, and some literature on its effect on labor force participation. Minimum wage legislation has extensively been used in developing countries as a social policy ostensibly to improve the well being of the poor.

Empirical evidence on price effects will help to answer the question of who pays for the higher costs associated to a minimum wage increase: firms, consumers, or unemployed. Employers facing higher labor costs respond by reducing profits, reducing employment, or raising prices.

- Profits: Many people assume that minimum wages will be paid out of profits. There is very little empirical evidence to support this assumption (Card and Krueger, 1995), but economic theory suggests this does not occur. Low wage firms are usually small firms in highly competitive markets and are not sufficiently profitable to absorb the extra costs. Even among larger and more profitable firms, capital is highly mobile and will flow to wherever profits are higher.

- Employment: Most of the minimum wage literature has focused on employment effects, which implicitly assumes that output prices are given on a competitive market, and that firms lower employment as a result of a minimum wage increase. This hypothesis, however, has been broadly dismissed in the 
literature. In his survey, Brown (1999) remarks: "the minimum-wage effect is small (and zero is often hard to reject)". While there is yet no consensus, small employment effects, clustered around zero, are becoming prevalent in the literature (Brown, 1999).

- Prices: There is very little empirical evidence on the effects of the minimum wage on prices. There has been considerable effort to reconcile the standard theory prediction of employment decrease in presence of wage increases with the available empirical evidence (Card and Krueger, 1995). However, little attention has been paid to the equally important theory prediction that an industry wide cost shock will be passed on to prices.

Employment will not be affected if firms are able to pass through to prices the higher costs associated to a minimum wage shock. Constant prices are a reasonable assumption for an industry where firms affected by the increase compete with firms not affected. However, an increase in the minimum wage represents an industry wide increase in costs. With employment and profits unaffected, higher prices are an obvious response to a minimum wage increase.

Absent employment losses, the minimum wage is just a program that transfers money from one group to another. The effectiveness of this transfer as an antipoverty program is a question of redistribution. If the poor are the consumers of minimum wage labor intensive goods, or if these goods represent a large share of their consumption bundle, then minimum wage increases might hurt the poor. Moreover, if minimum wage increases cause inflation, they might hurt rather than aid the poor, who disproportionately suffer from inflation.

During transition to market economy, Romania has implemented a legislation of minimum wage in several acts of labor market settlement. As in other similar cases in Romania, there were sometimes much more debate about minimum wage topic than its real economic effects. Even so, actual level of minimum wage in Romania is about 149 euro, the last bat one (Bulgaria) in E.U. The minimum wage level is only $35,3 \%$ by average wage level. In these circumstances, the impact of minimum wage over labour market, or over other macroeconomic variables is quite small. Nevertheless, the employer feels a little fear about their financial perspective in the short time future in event of an increase of minimum wage level.

\section{Methodology}

We came up with the idea of developing this model as a result of the contradictory results of the econometric tests regarding the macroeconomic impact of the minimum wage increase in Romania, between 1999 and 2009. Thus, the minimum wage does not cause any increase in the average gross nominal earning, but it rather helps to reduce its growth rate. As can be seen from equation 1 , the average gross nominal wage has an oscillating, highly inertial dynamic and its growth is hampered by the minimum wage of lag 4 (namely with an one year delay - the data being quarterly). Other factors such as inflation rate, unemployment rate, or the activity rate among young people (aged 1524 years) have a negligible influence.

Eq.1: DLNW $=0.036940-0.419944 * \operatorname{DLNW}(-1)-0.144450 * \operatorname{DLNMW}(-4)+0.008499 * \mathrm{I}(-1)+$ $0.005558 * \mathrm{I}(-4)-0.013469 * \mathrm{DU}(-2)+0.004667 * \mathrm{DX}(-3)$

where:

- DLNW: first order difference of the logarithm of average gross nominal wage

- I: inflation rate

- DU: first order difference of unemployment rate

- DLNMW: first order difference of the logarithm of national minimum wage 
- DX : first order difference of activity rate for the 15-24 year old age group.

Under these circumstances, it is natural that the minimum wage does not affect the consumer price index (CPI). As shown in equation 2 , the CPI rate is highly inertial and it is sustained only by the dynamic of the producer price index (with lags of 1,2 and 4 according to different types of production cycles in the economy).

Eq. 2: DLNCPI = 0.128251-0.537454*DLNIPC(-1) - 0.035743*DLNMW(-1)- 0.063920*DLNMW(5)-0.211742*DLNIPP(-1) - 0.227481*DLNIPP(-2) - 0.165368*DLNIPP(-4) - 0.029772*DLNIW(-4) $-0.0057829 *$ DLNIW(-5)

where:

- DLNCPI: first order difference of the logarithm of consumer price index

- DLNPPI: first order difference of the logarithm of producer price index

- DLNMW: first order difference of the logarithm of national minimum wage
- DLNIW: first order difference of the logarithm of labor productivity index

However, increasing the minimum wage rate has some impact on employment in terms of breaking it (decreasing, as shown in the chart 1 ) with lags of 3 and 4 (equation 3 ).

Eq. 3: DLNN $=0.01599478184-0.2673027232 * \operatorname{DLNN}(-1) \quad-0.2797594964 * \operatorname{DLNMW}(-3) \quad$ $0.197517803 * \operatorname{DLNMW}(-4)+0.01668939837 * \operatorname{LNI}(-1)$

where:

- DLNN: first order difference of the

- LNI: logarithm of inflation logarithm of employment rate for the 15-64 year old age group.

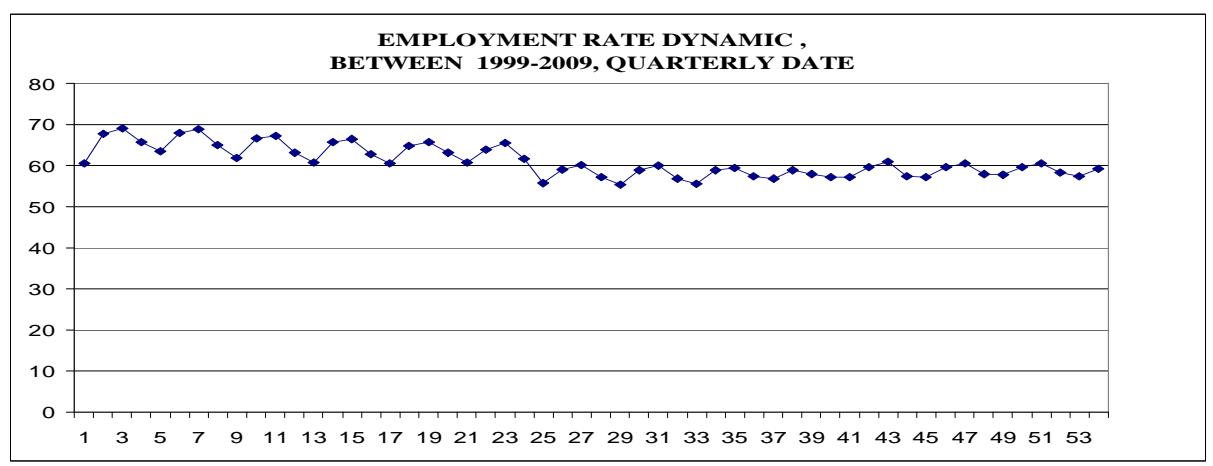

Fig 1. Employment Rate Dynamic between 1999-2009, in Romania

Combined with equation 1 , this behavioral equation shows that the annual minimum wage increases generally reduce the employment level when setting the new level with an even higher correction after one quarter. This suggested to us that the companies in Romania are trying to take up the annual minimum wage increases shocks by employment adjustments. However, a survey carried by the National Scientific Research Institute for Labour and Social Protection (NSRILSP) on a national sample of companies in 2008, reveals that less than $10 \%$ of the Romanian companies have adjusted their employment level due to the increment of the minimum wage in the last 
three years. It is true that the financial prospects of the Romanian companies in 2009 are more sensitive to any increments of the minimum wage. Thus, between $29 \%$ and $34 \%$ of the Romanian companies (depending on their size) are highly concerned about the possibility of a financial difficulties increase in case of an increment of the minimum wage in 2009. In fact, filling in the series of data with the last quarters of 2009, shows a stronger influence of the minimum wage on the employment rate as opposed to the econometric tests that addressed only the first quarter of that year.

These elements have suggested the idea of a shock absorption behaviour regarding the minimum wage increase by a priority adjustment of the wage fund of the companies in Romania. In order to describe this behaviour, we developed a fuzzy sets model that is structured based on the companies' typology used in the survey mentioned above: micro, small, medium and large businesses.

\section{The Fuzzy Model}

The inaccuracy and the uncertainty of the information needed to optimize the budgets are appropriate for a fuzzy approach to the companies' behavior regarding minimum wage shock absorption. Thus, the companies are not aware of the minimum wage future level or of the time of its enforcement. The companies are only aware of the minimum wage current level and of the trade unions' salary increase demands regarding the increment of this salary level. Some companies may be familiar with the employers' offer regarding the minimum salary level. Furthermore, companies do not know yet the implications that the new minimum wage level may inflict on the other categories of wages. Given that the business plans and the cash flows are annual and multi annual designed, any delay in adopting the new minimum wage level is a potential saving for the companies' salary budgets. In conclusion, we can say that the companies are aware of the real wage negotiation margins, they can estimate the most likely outcome of the negotiations between employers and trade unions, but they do not know when the new minimum wage level will be adopted, nor the implications of this level on other types of wages they pay (depending on their negotiations with the trade unions). Under these conditions, a fuzzy approach to the companies' behavior to optimize the salary budgets is the most appropriate one.

\section{Model Assumptions:}

$>$ Companies minimize both the costs and the budgets;

$>$ Companies know the boundaries between which they negotiate the minimum wage, but do not know exactly what the new minimum wage level is, nor when a new ratification may occur.

Companies do not know the precise implications the minimum wage may inflict on other categories of wage they pay.

Companies are trying to protect their market position and they are even willing to adjust the mark-up.

> The large companies are expected to make a market conjunction speculation, thus, protecting or even increasing the mark-up margin.

\section{Model Structure:}

Since the description of companies' behavior is based on a survey on a nationally representative sample, we will consider the types of companies used in the model as specific companies. From this perspective, we have four types of company structures (micro, small, medium and large companies), and two behavioral patterns:

$>$ Micro and small companies (small behavior - SB)

$>$ Medium and large companies (big behavior - BB).

The behavioral differences within each pattern are mainly related to budget adjustment possibilities in relation to the available resources. More specifically, these differences are related to how the budget divides itself in sub-divisions and work 
points. Thus, given the average size of the companies in Romania, (in most of the cases they are half the maximum of each category) we will use the assumption that small and micro enterprises have a single work point and a single budget, while the medium-sized and large enterprises can have several departments, work points or subsidiaries with associated budgets.

Minimum wage will be considered a random fuzzy variable (Proske, 2001) as its new level and the time of its enforcement are not known. In these circumstances, companies might think that the minimum limit is given by the current minimum wage level and the upper limit is given by the average of past minimum wage increases. Therefore, the most appropriate description of the minimum wage variable is a tridimensional fuzzy variable in which the time dimension has a stochastic nature, since the highest uncertainty is contained by the enactment temporal moment of this new salary threshold (using triangular fuzzy variables, Gherasim, 2005). This would oblige us to introduce a temporal dimension in the whole model, which would complicate it prematurely.

Since companies are not aware of the possible effects that minimum wage might have on other categories of wages they pay, we will use a fuzzy variable to describe the rest of the wage budget. In these circumstances the companies' wage budget will look as follows: $\mathrm{Wb}=\mathrm{Mw}+\mathrm{R}$

Where:

- Mw: will be a random fuzzy variable that describes the minimum wage costs

- R: will be a fuzzy variable that describes the rest of the wage budget
According to the basic assumptions of microeconomics, companies will seek to minimize the costs and, hence, the wage budget. In order to do this, companies dispose of another absorption level for the shocks generated by the minimum wage increment given by the total budget. Practically speaking, companies will try to offset the higher wage costs through savings in other expenditure categories. Of course, these adjustments should not affect the companies' current performances. Since the shock of the average wage growth occurs and disseminates on short term, we will take into account an inertial behavior of the companies, meaning that they will primarily be concerned about maintaining their market position and the production level. But as the companies' market position depends on their pricing strategy as well, it is very important to analyze how the wage increment shocks (caused by the increment of the minimum wage) affect the price of the goods that the companies produce. This means that companies will try to adjust these shocks in relation to market conjunction. This requires a reassessment of the mark-up margin in relation to the new costs level. From this perspective, the prices of the products made by the companies (own prices) can be described as fuzzy variables, because they involve a summation of fuzzy variables - the average cost level (a fuzzy variable by definition since budgets are such type of variables), and the mark-up margin (since the company does not know the exact implications its price strategy has). Thus, the companies' decision to adjust budgets and, therefore, prices can have implications both on the level of the average gross nominal wages and on the general level of prices. The budget adjustment means and the macroeconomic possible implications are described in the following figure (Fig. 2). 


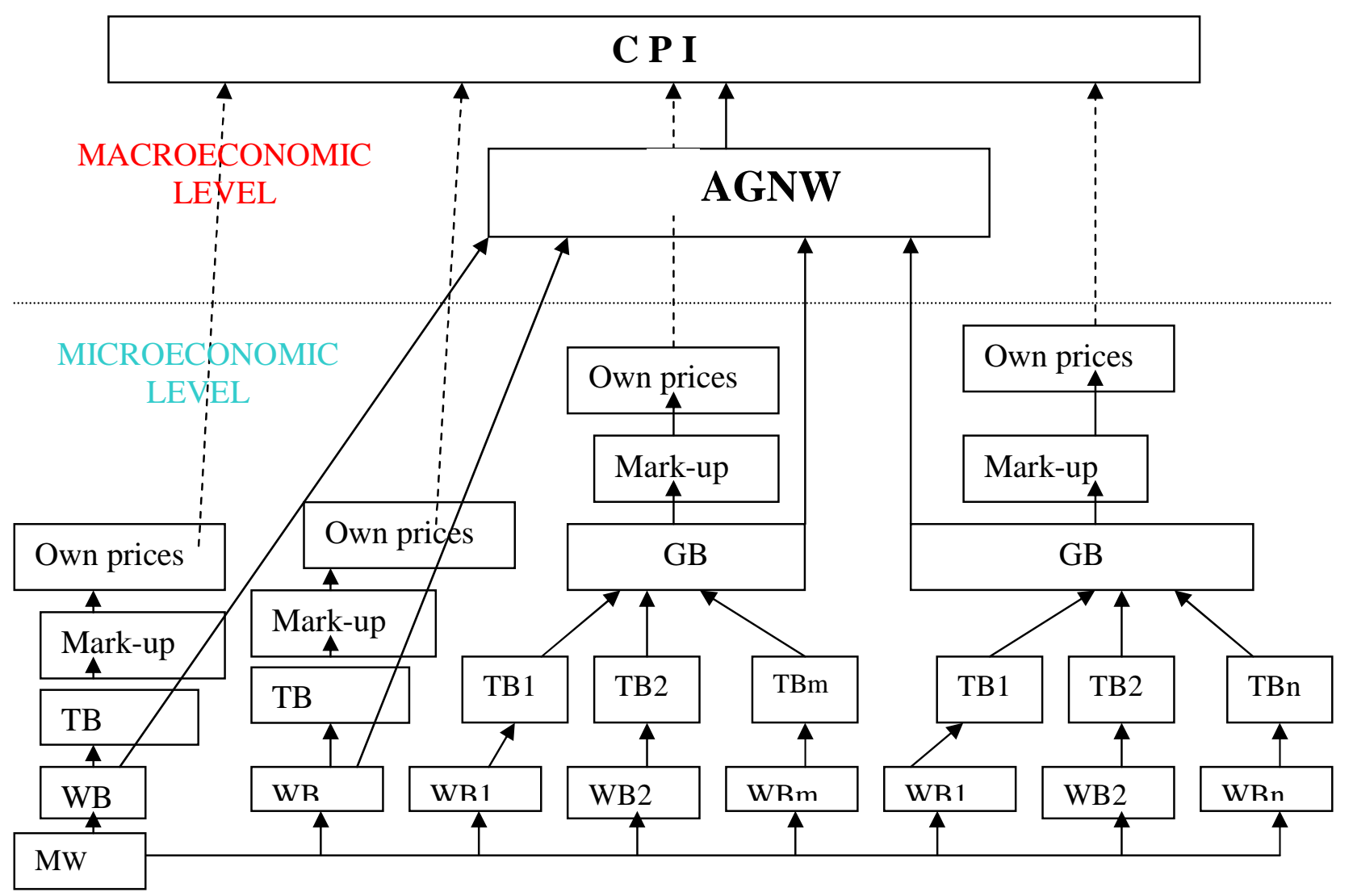

Fig 2. Structure of Fuzzy sets Model.

Types of Dissemination of the Minimum Wage Shocks.

Assuming two different patterns of behavior of the minimum wage increase shock absorption, we will have two ways of describing the dissemination of these shocks:

\section{$\checkmark$ Pattern SB (Small Behavior)}

for micro and small companies: the minimum wage shock may be more important and unpredictable, given their more limited resources and the way they perceive the minimum wage shock (according to the survey). In the first phase, there will be an attempt to absorb the shock on the budget salary level (on the account of the savings with direct and indirect wage costs). Then, there will be an attempt to absorb the shock on the total budget level on the account of the reduction of some expenditure categories other than the salary ones. In relation to their market position, companies will seek to preserve or even reduce their mark-up margin. Thus, the minimum wage shock will have two ways of disseminating on the macroeconomic level. A direct one to the average gross nominal wage, in relation to the balance between micro and small companies in terms of wage costs on the macroeconomic level. The other way of shocks dissemination is indirect, through the total budget, the mark-up and the own prices in relation to the contribution of the products made by these companies to the current consumer basket.

\section{$\checkmark$ Pattern BB (Big Behavior)}

In the case of medium and large companies, the dissemination way will be similar to the previous one, with the exception of the presence of an additional level of the general budget and of the existence of several budgets and wages of different sections and 
work points. The ability of these companies to be more flexible in terms of absorbing the minimum wage shocks will be taken into account. In addition, such companies have other options to address the margin mark-up, but also influence both the average gross nominal wage and consumer prices level (and therefore the CPI).

We should keep in mind that both types of behavior show that companies are not directly concerned with inflation, which is considered to be just a negative externality of the business environment, but with the maintenance of the cost level and their position on the market. However, the failures of their strategies to absorb the minimum wage shocks have a significant impact on the inflation level (directly or indirectly). An extension of the degree of failure will lead to an increase of the inflationary risks in the economy.

\section{Model Description}

To make it simpler, we will assume that the companies are on all levels primarily interested in maintaining the status quo. This means that their main objective is to minimize the budget, while maintaining the turnover rate or maximizing the profit are secondary objectives in the short run. Knowing the business environment, the balance of power between trade unions and employers, the workers' behavior, the political and social environment, the managers can make vague assessments about the potential impact of increasing the minimum wage. When describing these types of behaviour, the authors took into account the responses the economic agents gave in the survey conducted by NSRILSP on a national sample. Thus, the model involves a chain of several levels of decision:

- L1: the level of the base salary budget

- L2: the level of the total budget of the economic unity

- L3: the level of the general budget of the company (medium and large)
- L4: the level of the mark-up and prices

- L5: the first macroeconomic level - of the impact the wages paid by companies have on the average gross nominal earnings

- L6: the second macroeconomic level - of the impact the companies' prices have on the Consumer Prices Index

\section{Pattern SB}

The presentation of the model's levels will begin with the micro and small companies behavioural type - pattern SB.

- Level 1: The wage budget $\mathrm{Wb}$ is a fuzzy set given by the sum of two subsets:

- Mw: minimum wage costs

- Rw: other wage costs

Minimum wage costs will be the product of a fuzzy random variable and the constant $\mathrm{k}$ (meaning the number of workers paid with a minimum wage):

$\mathrm{Mw}=\mathrm{k}^{*} \mathrm{mw}$

where:

- $\mathrm{K}$ : the number of workers paid with the minimum wage

- Mw: random fuzzy variable that describes the minimum wage

The Wb set is described by:

$W b=M w+R w$

$\boldsymbol{M} \boldsymbol{w}=\left\{(x), f_{M w}(x) / x \in\left(i n f^{x}, \sup ^{x}\right)\right\}$

where:

- $\mathrm{f}_{\mathrm{Mw}}(\mathrm{x}): \mathrm{Mw} \rightarrow[\mathbf{0 , 1}]$ the membership function of the fuzzy set of the minimum wage costs

- $\inf ^{\mathrm{x}}, \sup ^{\mathrm{x}}$ represent the lower limit and respectively the higher limit of the variation 
interval of the possible values set of the minimum wage

The Rw set of the other wage costs will look as it follows:

$$
\boldsymbol{R} \boldsymbol{w}=\left\{(x), g_{R w}(x) / x \in\left(\inf f^{x}, \sup ^{x}\right\}\right.
$$

The membership function of the fuzzy $\mathrm{Wb}$ set will be given by:

$$
h_{W b}(x)=\operatorname{Min}\left[f_{M w}(x)+g_{R w}(x)-f_{M w}(x) g_{R w}(x)\right]
$$

This membership function has been corrected by adding the minimization condition of the budget in the form of the membership function describing the sum of some fuzzy sets.

- Level 2: The total budget is given by:

$T B=W b+R b$

The membership function of the total budget set (TB) will be:

$$
l_{T b}(x)=\operatorname{Min}\left[h_{W b}(x)+\gamma_{R b}(x)-h_{W b}(x) \gamma_{R b}(x)\right]
$$

Given the condition of the status quo in the short run behaviour of the companies, the restriction will be used so that the production value does not fall:

$\Delta Q=0$

- Level 4: The model does not include a Level 3 for micro and small companies. In Level 4, the total budget is turned into unitary costs, according to an accounting methodology for allocating costs. A $\Theta$ transformation operator will be applied on the total budget variable. This will also result in a fuzzy set of the unitary cost. In these circumstances, the price level of the representative product of the companies will be a fuzzy variable of the type:
$P=\left\{(x), \mu_{P}^{(x)} / x \in\left(i n f^{x}, \sup ^{x}\right)\right\} \quad(9)$

The membership function of this set will still be characteristic to a minimized sum, corresponding to the fuzzy sets sum of the unitary cost and the mark-up:

$\mu_{P}^{(x)}=\operatorname{Min}\left[q_{C}(x)+\Psi_{M}(x)-q_{C}(x) \Psi_{M}(x)\right]$

- Level 5: The impact of the wages paid by the companies on the average gross nominal wage can be simulated by the weighted contribution of wages to a weighted arithmetic mean operator. For this reason the average gross nominal wage level can be described as a fuzzy set of the type:

$\mathrm{Aw}=\left\{(\mathrm{x}), \rho_{A w}{ }^{(x)} \mid \mathrm{x} \in\left(\inf ^{\mathrm{x}}, \sup ^{\mathrm{x}}\right)\right\}$

The membership function of this set will be obtained as follows:

$\rho_{A w}(x)=l_{j}\left(\sum_{j} v_{w j}-\prod_{j} v_{w j}\right)$

where:

- Wi: the average wages paid by every type of company in the model.

- $\mathrm{Li}$ : the balance of the wage costs of every type of company in the total wage costs of the economy.

The impact of the new level of the gross nominal earnings on the consumer price index could be described by a fuzzy implication function, due to the indirect influence the wages have on inflation. Assuming a statement like "an increment of the average gross nominal earnings might cause inflationary pressures", the truth of it will be described by a composed membership function that will describe implication of the two events.

The membership function of the fuzzy sentence that describes the average gross 
nominal wage impact on the price level will be as follows:

$$
\Phi^{(\mathrm{Aw} \rightarrow \mathrm{Cpi})}=\Phi^{(\mathrm{nonAw} \cup \mathrm{Cpi})}=\operatorname{Max}\left(1-\rho_{A w}{ }^{(x)}, \zeta_{C p i}{ }^{(x)}\right)
$$

The membership function of the consumer price index $-\zeta_{\mathrm{Cpi}}(\mathrm{x})$ will be taken from the sixth level of the model.

- Level 6 The impact that the prices of the companies products have on the consumer price index will be described in a similar way to that in level 5. Thus, the membership function of the set of possible values of the CPI will be as follows:

$$
\xi_{C p i}(x)=l_{i}\left(\sum_{i} \mu_{I p i}-\prod_{i} \mu_{I p i}\right)
$$

Where:

- IPi $_{\text {and }} \mathrm{i}=1,2, \ldots$,

- S: are the price index of goods produced by a group of enterprises included in the sample for calculating the CPI.

\section{Pattern BB}

The other part of the model that describes the medium and large companies behaviour (pattern BB) will be described in a similar way with the following specific adjustments:

- Level 1: will be addressed the same way as the corresponding level in the first part of the model. There will be added an index number $\mathrm{k}$ for the budget of every work point/subsidiary.

- Level 2: keeps its behaviour description equations, noting the introduction of the same index number $\mathrm{k}$ for the total budgets of every work point/subsidiary.

- Level 3: It involves the fuzzy addition of the total budgets of each work point $(\mathrm{k})$ in a consolidated general budget. The membership function of this general budget Gb is given by:

$$
\xi_{G b}(x)=\operatorname{Min}\left(\sum_{k} l_{T b k}-\prod_{k} l_{T b k}\right)
$$

- Level 4 remains unchanged and levels 5 and 6 have already been described.

\section{Conclusions}

The companies' behavior is very important for establishing the wage level and for the persistence of the inflation pressures. As for the minimum wage, it is clear that it raises concerns for the companies. Even in the case of Romania where the minimum wage level is very low (35.3\% of the average wage level) and does not represent a problem for the companies, the prospect of a worse economic conjunction makes the estimation of this variable dynamics a serious concern. This is particularly so since, the further development of the economic situation showed an aggravation of the population's living standards and hence a higher pressure for an increment of the minimum wage. As the result of negotiations between trade unions and employers is very ambiguous, in terms of wage level and enactment time, a fuzzy approach to describe the companies' behavior regarding the absorption of the shocks generated by the minimum wage increments is the most appropriate solution. Obviously, the model proposed by the authors requires additional polish and the solving of some practical problems regarding the actual composition of the membership function forms, but it could represent a challenge for future research.

\section{Acknowledgments:}

This work has received the support of Romania CNCSIS grant 77/2010.

\section{References}

Adam, G. (2007). European Foundation for the Improvement of Living and Working Conditions, Social partners Agree to Minimum Wage Increase, Dublin. 
Ailenei, D. \& Târțiu, V. E., (2008). "A Regional Approach for Optimization of the Municipal Waste Management System Using Fuzzy Sets," Romanian Journal of Regional Science.

Andreica, M. E., Cristescu, A., Aparaschivei, L. \& Cătăniciu, N. (2010). Models of the Minimum Wage Impact upon Employment, Wages and Prices: The Romanian Case, Proceedings of the 11th WSEAS International Conference MCBE '10, Iași, Romania, june 2010;

Arrowsmith, J. (2005). European Foundation for the Improvement of Living and Working Conditions, Minimum Wages in Europe (online)., UK national contribution to comparative report, Dublin.

Brown, C. (1988). "Minimum Wage Laws: Are They Overrated?," The Journal of Economic Perspectives, Vol. 2, No. 3, pp. 133-46;

Brown, C. (1999). "Minimum Wages, Employment, and the Distribution of Income," Handbook of Labor Economics, ed. by 0 . Ashenfelter, and D. Card. Amsterdam; New York and Oxford: Elsevier Science, North-Holland, 2101-2163;

Brown, C., Gilory, C. \& Kohen, A. (1982). "The Effect of the Minimum Wage on Employment and Unemployment," Journal of Economic Literature, Vol. 20, pp. 487-528;

Card, D. \& Krueger, A. B. (1995). Myth and Measurement: The New Economics of the Minimum Wage, Princeton: Princeton University Press;

Carley, M. (2006). "Key Themes in Global Industrial Relations: Minimum Wages and Relocation of Production," European Foundation for the Improvement of Living and Working Conditions, Luxembourg, Office for Official Publications of the European Union;

Couso, I., Miranda, E. \& Cooman, G. (2006). A Possibilistic Interpretation of the Expectation of a Fuzzy Random Variable, Fuzzy Sets and Systems, September;
Cousoa, I. \& Sánchez, L. (2007). Higher Order Models for Fuzzy Random Variables, Fuzzy Sets and Systems, September; Esogbue A.M.D, Romash, V., (1970)., Dynamic Programming Process and Fuzzy Allocation, Technical Memorandum No. 202;

Gherasim, O. (2005). Mathematics of Triangular Fuzzy Numbers (in Romanian)., Editura Performantica, Iaşi;

Gindling, T. H. \& Terrell, K.(2007). The Effects of Multiple Minimum Wages throughout the Labor Market: The Case of Costa Rica, Labour Economics 14.

Gruetterm, M. \& Lalive, R. (2009). The Importance of Firms in Wage Determination, Labour Economics 16;

National Research Project no. 91-036, PNIIThe Impact of Minimum Wages on Employment and Wages Policy of Firm.

Neumark, D. \& Wascher, W. L. (2008). "Minimum Wages," Cambridge, Massachusetts: The MIT Press;

Project partners: National Scientific Research Institute for Labor and Social protection (NSRILSP). (coordinator).; Academy of Economics Studies Bucharest; Project Director: Cătăniciu N., PhD, 2008-2010

Proske, F. N. \& Puri, M. L. (2001). "Central Limit Theorem for Banach Space Valued Fuzzy Random Variables," Proceedings of the American Mathematical Society Volume 130, No. 5;

Zavodny, M. (2000). "The Effect of the Minimum Wage on Employment and Hours," Labour Economics 7. 